\title{
Local Knowledge, Public Policy and Poverty Reduction: A Review on Indonesia Experiences
}

\author{
Bayu Taufiq Possumah, Zikri Muhammad, Jaharudin Padli, Jasmi Abu Talib, Kamarul Md. Shah \\ School of Social Economic Development, Universiti Malaysia Terengganu (UMT)
}

\begin{abstract}
The community based Local knowledge, basically is an adaptation strategies that arise from within the community itself in fixing socially problem related to the life of society itself. Since local knowledge is the result of interaction between the community and the environment, it is needed to help the community living independently. Hence the local knowledge is the core of efforts to reduce poverty that exists and grows in the community and as the big part of from the process of poverty alleviation programs. The complexity of poverty not only can be overcome by purely economic approach, but it is associated with the dynamics of social, political and cultural that inherent in a community. The multidimensional problems requires synergy between government policy, community and local knowledge itself. This paper attempts to describes the frameworks of Indonesian policy to link the three sectors to empower the poor exit from poverty problem
\end{abstract}

Keywords: Local knowledge; Public Policy; Poverty Alleviation; Indonesia

\section{Background of Study}

As a country with large population, Indonesia known also as the largest democracy in Asia. Challenges for Indonesian government both central and local levels are quite large as well, how far they are able to practice good governance. The right strategy to achieve this good governance is the effectiveness in communicating with people and a way to realizing an effective communication with people is by using local wisdom in governance practices. Local wisdom or local knowledge can be defined as a richness of local cultures containing life philosophy. In Indonesia, local wisdom applies not only locally on a particular culture or ethnic but also cross-cultural or cross-ethnic thereby forming a national cultural values. For example, almost every local culture in the archipelago implements local wisdom that teaches mutual cooperation, tolerance, work ethic, and so on. In general, ethics and moral values embodied in the local wisdom passed down through the generations through oral literature (for example in the form of sayings and proverbs, folklore), and manuscripts

\begin{abstract}
Indonesia has approximately 252 million populations where rice as the main food almost in everywhere. Every year, a minimum of 33 million tons of rice, 16 million tons of corn, 2.2 million tons of soybeans, 2.8 million tons of sugar and 484 thousand tons of beef should be provided. In fact, numbers of poor people is still in a large proportion approximately as $11.4 \%$ of the population, thus the problem of increasing rice production and nutrition become a serious attention for the authority. Besides, uncontrolled conversion of 100 thousand ha agricultural land per year cumulate list of challenges to be faced by the government. Other alarming issues to be concerned such are distribution of uneven food, difficult to access the financial resource and information, the lack of use technology and limited access to the markets. Negative impacts of global climate change must also considered in order to increase food production in Indonesia. These are among the factors that led to high levels of poverty in Indonesia, especially in access-less areas to development.
\end{abstract}

Corresponding author: bayu@umt.edu.my 
According to Ritonga (2003), at least there are two important factors which essentially cause the failure of poverty reduction programs in Indonesia. First, poverty reduction programs tend to focus their efforts on the distribution of social assistance for the poor. This efforts difficult to resolve the existing poverty problem since the nature of aid is not to empower but even lead to dependence. Therefore, this aid program cannot be held continuously or regularly. The second factor is the lack of understanding on the causes of poverty itself. The existing development programs are not based on issues of poverty, which caused by various locally factors.

Generally, poverty in a community is similar to what found in other communities. The similar condition does not mean that same approach should be made to tackle poverty in a community. Each community has its own development character that not necessarily same as other communities. Development of community determines problems which occur in both type and dimensions of the society. This corresponds as well with the knowledge, technology, customs, and resources within the community. Thus, it is important to put more attention to the existence of local wisdom employed in a community economic empowerment and poverty reduction program. Therefore, government function essentially to create and implement policies for the welfare, educate, empower, and protect entire society then it is wise to optimize local wisdom in the implementation of government function.

\section{Local knowledge and Economic Empowerment}

Indigenous knowledge is knowledge generated from community life experiences and as a result of interactions with their environment over millennia. Indigenous knowledge covers virtually every field of human endeavor and usually varies from community to community; one unifying factor being that it is aimed at addressing challenges and solving perceived problems specific to each community (World Bank, 1994). Indigenous knowledge, contrary to widespread dismissal, is not static, but innovative in that it has been adapted over time in response to environmental changes and influences, and as a result of the need for improvement on strategies (Hoppers, 2002). Thus, indigenous knowledge differs from globally accepted knowledge which is often generated from universities and research institutions, acknowledged by the predominant global media establishments and often traces its roots to western knowledge systems (Oguamanam, 2008).

For some post-development writers, indigenous knowledge represents a possible alternative for progress among the world's rural poor. As Escobar $(1995,98)$ puts it: "[t]he remaking of development must start by examining local constructions, to the extent that they are the life and history of the people, that is, the conditions for and of change". Such approaches can be supported by careful ethnographic work capable of teasing out the complexities of the interrelationships established between communities and places (Herbert, 2000). This implies a change that comes from within communities themselves, having confidence in and deploying indigenous knowledge, among other things, to bring about economic and social progress. There is then a sense of the rural poor having a voice about progress which affects them, and outsiders listening seriously to what the rural poor have to say, learning from them, and respecting their realities and priorities (Chambers, 1983; 2001).

Economic empowerment implies the act of instituting environmental structures to facilitate individuals in bringing change in their social and economic status. Individuals are said to have become economically empowered when they are provided the tools they need in order to work towards self-reliance. According to the Organization for Economic Cooperation and Development (OECD), "economic empowerment is the capacity of women and men to participate in, contribute to and benefit from growth processes in ways that recognize the value of their contributions, respect their dignity and make it possible to negotiate a fairer distribution of the benefits of growth" (OECD, 2011). Thus, economic empowerment if widespread within a society invariably translates to economic growth as strategies that emphasize entrepreneurship has been increasingly accepted and proven to be a veritable channel for the generation of economic growth and innovation across economies, both developing and developed (Acs, Desai, \& Klapper, 2008). And in the words of Audretsch (1997). 'Entrepreneurship makes an important contribution to economic growth by providing a conduit for the spill-over of knowledge that might otherwise have remained un-commercialized'

\section{Poverty Reduction and Public Policy in Indonesia}

Public or government policy in general defined as everything to do with the government's decision, either program, regulation or others. A policy will run as expected if supported by a various factors, such as the accuracy of policy in 
line with the public needs and supported by responsibility and participatory of society, as well as compliance with the law and regulations. But as a constitutional state, it is not easy to run the actual function of the law itself without awareness among citizens. This awareness is not only limited to obedience, but in-depth understanding towards the goal of a policy is the essence of a decision, such as the accuracy of decision-making, proper implementation, and supported by various influence elements.

In term of poverty reduction, the Indonesian government strategy through national development applies the Four Track Strategy; pro-growth, pro-job, pro-poor and pro-environment. These four track strategies are intended to promote equitable economic growth through the expansion of employment opportunities, poverty reduction, and maintain sustainable growth with an emphasis on environmental sustainability. Social and economic gaps are expected to be well reduced under this strategy. The national development agenda has been included in the medium term development plan (RPJMN) 2004-2009 and 2010-2014. This is also reinforced in the national development plan in RKP 2013 with the theme of "Strengthening Domestic Economy for the Improvement and Expansion of Public Welfare".

In the meantime the government strategy in reducing poverty is focused through three clusters of poverty reduction programs, namely:

- First cluster: Aid program and integrated social protection based on the family which aims to perform basic rights, reduce the expenditure burden and improve quality of life for poor families. The main programs are rice for the poor (Raskin), National health insurance (Jamkesnas), Family Hope Program (PKH), School Operational Assistance (BOS), and Poor Students Aids (BSM).

- Second cluster: poverty alleviation program based on community empowerment through PNPM Mandiri program which aims to develop the potential and strengthen the capacity of the poor to engage in the development, improve the income and standard of living through efforts and cooperation to achieve empowerment and self-reliance where community groups or poor districts as the target.

- Third cluster: poverty alleviation program based on economic empowerment of micro and small enterprises (MSEs), which aim to provide wider access to capital source and strengthening the economy for businesses small and micro-scale through business loan scheme (KUR)

By clustering level it is expected the poor families who initially become beneficiaries at first cluster program will be able to meet their basic needs and then move to receive second cluster program to continue to improve their lives in purpose to utilize the cluster program 3 and eventually expected to be free from the bondage of poverty. To strengthen the third cluster program, the government has launched the fourth cluster since 2011 which consist of low price housing program, cheap public transport, Hygiene water for everyone, cheap and economical electricity, as well as life improvement of fishermen and suburban community. For those reasons, allocation budget to meet the development impediments, Indonesian government has determined that the local knowledge and local wisdom should be emphasized and use as a basis of sustainable socio-economic policies. Here, Indonesian government would like to show the importance of recognition and respect for the role of local wisdom and knowledge in the development of economic sector because it has been widely proven that local wisdom when adopted into policy would results better impact.

Rules and policies that are "one size fits all" should be reduced. It is necessary to create, nationally and locally rules which means that the rules apply in the context of smaller scope with local knowledge and local wisdom. This localized policies based on local knowledge and local wisdom. There are diversity aspects in addition to unity (oneness). What occurred during this time is more emphasis on unity, thus it is necessary to emphasize this aspect of diversity also.

\section{The Indonesian Government Policy towards Local Knowledge and Community Economic Empowerment}

The purposes of community empowerment are to establish self-reliant individuals and communities. Self-reliance means ability to think, decide and do something that is deemed appropriate to solve problems encountered with the use of own capabilities. The purposes of community empowerment: (i) to improve living standards, (ii) to increases confidence, (iii) to provides freedom for everyone to engage the Community Based Development (CBD). There are several main characters of CBD, as follow: CBD resource community based, CBD community participation based. These CBD sustainable community empowerment based can be seen from two points of view: deficit based approach 
which focus on the problems that exist and efforts to solve the problem, and strength based approach which focus on the potential and capabilities of either community or individual to improve the quality of life. The roadmap of Indonesian in developing local knowledge and community economic empowerment may be seen as following figure:

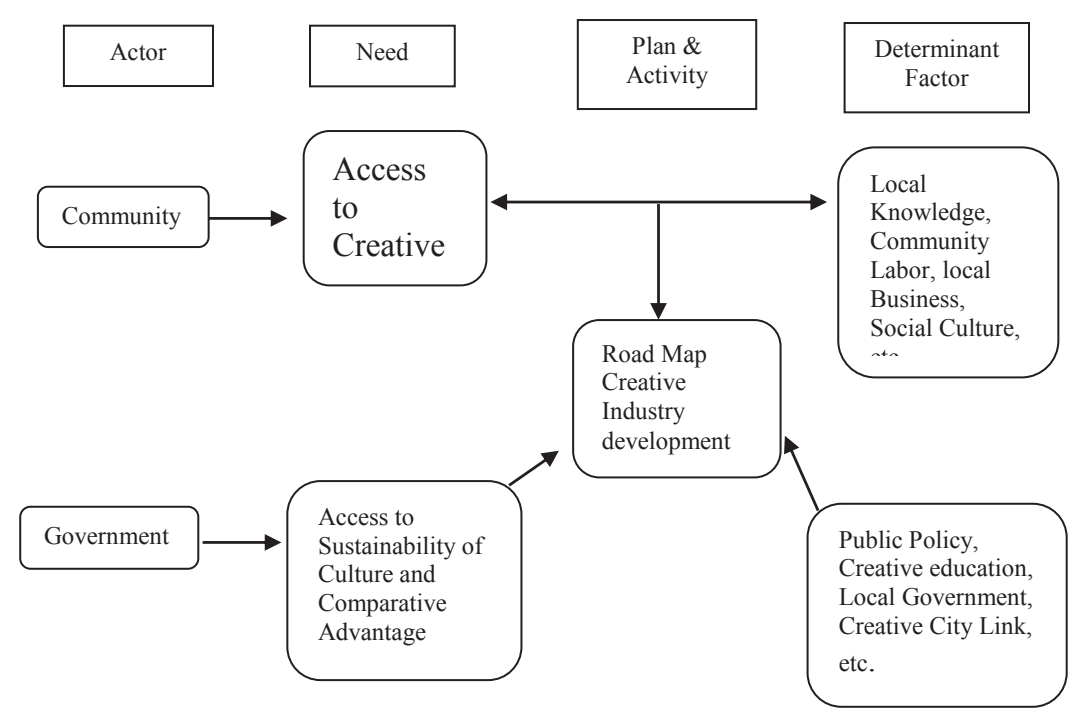

Some of the policies that have been carried out by Indonesian government to make the local knowledge as one of the pillars in the economic and social development, as follow:

\subsection{Strengthening The Local Government}

Based on the data from Badan Pusat Statistik, number of poor people (population with expenditure per capita per month below the poverty line) by September 2016 reached about 27.76 million (10.70 percent) or a decrease of 0.25 million compared to March 2016 which amounted to 28.01 million (10.86 percent). The percentage of poor people in urban areas in March 2016 around 7.79 percent and fell to 7.73 percent in September 2016. Similarly, percentage of poor people in rural areas fell from 14.11 percent in March 2016 became 13.96 percent in September 2016.

Although during the period of march 2016-september 2016 the percentage of poverty as overall has declined, but the number of poor people in urban areas rose as many as 0.15 million people (out of 10.34 million people in March 2016 into 10.49 million in September 2016), while in the rural area fell as many as 0.39 million people (from 17.67 million in March 2016 into 17.28 million in September 2016.

Focusing at the poverty level and the number of which varies in each province, then the effectiveness of poverty alleviation programs cannot be separated from the active role of local government, both at provincial and district/city. Conceptually, the National Poverty Reduction Strategy is important but not sufficient. It is required the active participation of local government and community as well to sharpen the program and the target beneficiaries through the Regional Poverty Reduction Strategy (PRSP) which includes initiatives and local wisdom. Within the framework of the decentralization, central government has delegated broad authority in various fields to the local government, except six major powers (foreign affairs, defense, security and justice, fiscal and monetary, religion). As a unit of government that is closer to the community, the local government is more able to understand and have the ability to implement programs in accordance with the characteristics and needs of communities in the particular region, so that public services can be provided in larger quantities (production eficiency), resources are allocated more effective and 
accountable (eficiency and accountable allocation) as well as more community participation and the aspirations are more accommodated including the most needy communities.

Those are the reason to give more space to the local government such the rural administration authority to strengthen their role. Eventhough the scale is small and locally which only covers the administrative area of the village itself. Yet the rural administrator has the right and must be participated in determining the direction of national development in general and its own rural development in particular. Rural administration authority formally has to make regulations and able to force the rules legally, but apart from the standpoint of the formalities, each rural traditionally has the wisdom in problem solving. Therefore, the rural administrative authority as a sub-formal institution should not necessarily lead to implement any general operational standards and country's provision. But the rural administrative authority have to adjust wisely and stand along with wisdom and norms that exist in the area differently, therefore every state agency at the bottom level should have flexibility in implementing the policy and governmental functions. This is exactly what lies behind a policy, program or any form of rural authority decisions should not be shaped as rural regulations that bind formally by the positive law of the country. But the rural are has its own traditional norms for any solution to determine the direction of its development, but still expected to play an active role as public servant, facilitator and initiator of solving public problems formally or informally.

\subsection{Community Based Natural Resource Management Approach}

Community-based nature of resource management (CBNRM) or community based natural resources management approach is a biological strategic management $(\mathrm{SDH})$ in where people can actively participate and play a role in tackling the problems that affect SDH. Thus in this case CBNRM concerns much with the participation of local communities in utilize and maintain SDH in the surround area. CBNRM is an example approach in natural resource management system that considers aspects of justice, equity and welfare of the community around SDH continuously (Jatna Supriatna, 2008). The role of local community in CBNRM is ranging from planning, implementation, monitoring and evaluation. In general, the public role itself determined by three things: 1) the extent to which local knowledge can be appreciated and utilized in forming a good conservation management system; 2) how big local communities concerns about the nature which push towards an effort to preserve and manage natural resources as well as the environment inside and outside the region, and 3) how much benefits (material 1 and non-material) that can be achieved by society from the conservation area so that its presence has a favorable value continuously. Although there is no success-lesson yet but CBNRM concept might be as reference in building a conservation area management model in favor of public welfare without ignoring the preservation of its biodiversity. Some of issues that are the main target of CBNRM, namely: 1) open access for public (local) and other stakeholders in term of information and management; 2) provide opportunities for people to improve their living standards through the use of available biological resources which will encourage them to continue to maintain its existence; and 3) strengthening the position of the public and other stakeholders in the processes of government policy-making related to natural resource management. To support its success, there are several principles in implementing the CBNRM, namely principle of community development, principle of equality, principle of environmental orientation, principle of respect for the local knowledge/tradition and principle of gender recognition (Jatna Supriatna, 2008)

\subsection{Development of Local Food}

BPS argues, the role of food commodities to the poverty line is much greater than the role of non-food commodities (such as housing, clothing, education, and health). The role of food to the poverty line in September 2016 pointed at 73.19 percent, that condition was not much different from the situation in March 2016 which amounted 73.50 percent. The type of food commodities with the biggest influence on the value of poverty line in urban and rural areas are rice, tobacco, beef, eggs, sugar, instant noodles, onion and soy beans.

Therefore one of the strategic policies is to achieve the economic independence by enhancing the strategic domestic sectors. One of that strategic sector is agriculture reformation with agenda to improve food sovereignty for community. Food sovereignty is reflected on the regional power to regulate independently that needs to be supported by food security, food policy setting, and able to protect and improve the life of farmers and fishermen as the main actors in that sector. 
According to the mandate which set out in nawacita, the agriculture ministry has targets to be achieved in 2016 namely the expansion of paddy field to 200.600 hectares, expansion of dry land to 250,000 hectares, rehabilitation of tertiary irrigation to 650,000 hectares, 1,000 units shop for Indonesia farmer, restoration and optimization of 275,000 hectares soil fertility, escort, mentoring and monitoring, constructionof 39 warehouses, better regulation of food imports, improvement farmers capability, development of organic rural farming area.

In the meantime of staple food development, development of local food is also expected to support food sources and consumption diversities in food compliance in Indonesia. Traditional food and specific location are directed to develop a more commercial and to support these steps, a local food processing technologies have been and will continue to be developed to produce fast food. Various types of local food that can be developed such as sago which can be transform into a variety of food/groceries like papeda, sinonggi, sago rendang, sago lemak, sago lempeng, kapurung, sampolet, gobak sago, and rice analog. Cassava can be turn into such like tiwul, enbal, kasuami, kabuto, aruk rice, cassava rice, and rice analog. Corn can be turn into corn bose, binte biluhute, kabusunosu, maize, and rice analog.

A variety of things should be done to develop the local food are (1) change the mindset of people that meal does not have to always rice, (2) promoting, campaigning, and socialize intensively for local consumption, (3) improve the image of local food through more practical process, simple presenting, eye catching appearance, (4) cooperating with the private sector or public-private partnership in the development of local food, and (5) launch a campaign to reduce food waste.

\subsection{Development of local culture}

Preservation model of local culture through the cultural village need to be developed more with destination management approach. This is because the cultural village that contains culture resources has the opportunity to become a tourist destination. Some strategic steps that can be done based on the tourism destination management (Damanik, Janianton and Frans Teguh, 2013: 30), as follows:

- Leadership and coordination. Strengthening cultural village institutions to carry out management functions of cultural village

- Cooperation and partnerships. Strengthening communication and coordination forum between each cultural village and the relevant local government in order to creates continuous synergies.

- Research and planning. Strengthening development of cultural villages as a form of program, conduct assets inventory periodically and socializing the results of research and develop programs that have been carried out by the provincial government regarding management of cultural village

- Community assistance. The involvement of local government in this regard through various facilitation activities to mobilize all assets held in the cultural village environment include support and participation in the community

- Product development. Strengthening the cultural potential both tangible and intangible that has a sale value as a commodity culture

- Marketing and promotion. Strengthening marketing and promotion through cultural activities for instance cultural competition or cultural festivals regularly

\subsection{Muffling the impact of globalization on local Knowledge}

\section{Re-humanization}

Restoring human dignity in the globalization era should be adjusted to the adaptability of the population concerned. The development of religious values, ethics, law, and policy are slower when compare with the development of information and technology. Therefore these issues must be addressed more humanist which means it should be viewed as a whole picture, physically and mentally. Thus development should always lead to the realization of human welfare both physically and mentally. If this is ignored than the destruction of human civilization cannot be offset by re-humanization program therefore all parties should take part and contribute positively

\section{Ability to Choose}

Every technical thing will be done straight away, does not disputed and filtered based on the values of humanity. By means that if it is supported by moral aspects of religious, social, and related aspects that should 
determine what may be researched and developed then does not executed otherwise in accordance with the local wisdom.

\section{Revitalization}

Positive effort is needed to prevent bio-cultural sustainable distortion, because development leads to a new culture in the future. Revitalization will be much affected either positively or negatively by inside and outside factors of the country.

\section{Conclusion}

Facing the challenges of poverty prospects from local knowledge in the future relies on the utilization and empowerment of local knowledge to manage natural resources and its environment. Knowledge about local knowledge in the communities inheritable from generation to generation, as well as innovation and technology also affect the sustainability of local knowledge in the future. Government as the authority must enforce policies related to the use of adopted technology and diffusion of technologies that protect the environment and natural resources through local knowledge. There are many opportunities for the development of archipelago local knowledge discourse. In addition, local knowledge can be approximated from the values that flourish in it such as religious value, ethical value, aesthetic, intellectual or even other values such like economy, technology and more. Then the treasure of local knowledge become a fertile land to be explored, discussed and analysed in order to increase income and reduce poverty in local communities considering the factor of global developments happened so rapidly. In order to create depth linkages between local knowledge and poverty reduction program there are several important components that need to be intervened are as follows: (1) pro-poor anti-poverty policies, (2) social capital and human resources (improvement of knowledge and skills, social and institutional relations, mutual trust), (3) access to land, (4) the provision of employment, and (5) special attention to women's lives as heads of households (widows) and malnourished children due to cultural factors in the countryside.

\section{Acknowledgement}

This paper is part of the outcome for the Long Term Research Grant Scheme (LRGS) program on "Conceptualizing Local Knowledge: A Study on Sustainable Values of Local Wisdom and Indigenous Sciences" specifically project (203/PTS/6727003) on "Innovative Local Knowledge Repository Support System"

\section{References}

1. Audretsch, D.B., Keilbach, M.C., Lehman, E., 2006. Entrepreneurship and Economic Growth", Oxford University Press, Oxford, p. 227.

2. Audretsch DB and Thurik AR (1997) Sources of Growth: The Entrepreneurial versus the Managed Economy. Tinbergen Institute Discussion Paper TI 97-109/3, Tinbergen Institute

3. Badan Pusat Statistik (BPS), Indonesia

4. Briggs, J. (2005) The use of indigenous knowledge in development: problems and challenges. Progress in Development Studies 5(2):99-114

5. Chambers R (1983) Rural development: putting the last first. (Longman, Harlow)

6. Departemen Sosial RI. (2006). MemberdayakanKearifan Lokal bagi Komunitas Adat Terpencil

7. Herbert S (2000) For ethnography. Progress in Human Geography, 24, 550-568

8. Escobar A (1995) Encountering development: the making and unmaking of the Third World. (Princeton University Press, Princeton NJ).

9. Organisation for Economic Co-operation and Development (OECD). 2011. Women's Economic Empowerment: Issues Paper. Paris: OECD-Development Assistance Committee.

10. OECD. (2014).

11. Oguamanam, C. (2008). Local Knowledge as Trapped Knowledge: Intellectual Property, Culture, Power and Politics. Journal of World Intellectual Property II , 29-57.

12. Ritonga, H. 2003. Kemiskinan dan Kesenjangan Ekonomi Antar Wilayah. Makalah disampaikan pada Konsultasi Regional Produk Domistik Bruto se Propinsi Riau, di Kepri Juli 2003. 
13. Women Economic Empowerment . Retrieved March 3, 2014, from Organization for Economic Cooperation and Development: http://www.oecd.org/dac/gender

14. Zulkarnain, A.Ag., \& Febriamansyah, R. (2008).Kearifan Lokal dan Pemanfaatan dan Pesisir., Jurnal Agribisnis Kerakyatan, 1 